\title{
Solution to elemental pub quiz challenge
}

\section{Juris Meija ${ }^{1}$}

Published online: 2 April 2020

C) Crown copyright in right of Canada 2020

The joint winners of the Elemental pub quiz challenge (published in volume 411 issue 25) [1] are: Anita Röthke and Mareike Renger, Physikalisch-Technische Bundesanstalt, Braunschweig, Germany.

The award entitles the winning group to select a Springer book of their choice up to a value of $€ 100,-$.

Our Congratulations!

1. Which element is:

a. New (neon, name etymology)

b. Fake (technetium)

c. Not alone (antimony)

d. Heavy (barium)

e. Unstable (astatine)

f. Evil (cobalt)

g. Strange (xenon)

2. Which element was:
a. Sweet (beryllium was previously known as glucinium)
b. An old man with scythe (lead, in alchemical allegories)
c. Brine, fleetingly (bromine, first named muride, also chlorine)
d. Purified by the grey wolf (gold, in alchemical allegories)
e. Discovered in the nose of the fairy hill (strontium, from village name)
f. One aluminium (gallium, Mendeleev's eka-aluminium)
g. Two manganese (rhenium, dvi-manganese)

3. Which:

a. Element relates to torment (tantalum)

This article is the solution to the Analytical Challenge to be found at https://doi.org/10.1007/s00216-019-02057-w

Juris Meija

juris.meija@nrc.ca

1 National Research Council Canada, 1200 Montreal Road, Ottawa, ON K1A 0R6, Canada b. Element has its own sura (iron)

c. Element lost a letter after World War II (protactinium, known as protoactinium before 1949, also lutetium or sulfur whose spelling changed)

d. Goddess melts in hell (selenium, melts in liquid sulfur temperatures)

e. Capital resists acids (hafnium, named after Copenhagen)

f. Capital won over a constellation (lutetium, named after Paris, replaced cassiopeium, named after constellation)

g. Daughter won over the United States of America (niobium, named after daughter of Tantalus, replaced columbium, named after the USA)

4. Figure out:
a. 1 (iodine, $1=\mathrm{I}$ in Roman numerals)
b. 5 (vanadium, $5=\mathrm{V}$ )
c. 55 (livermorium)
d. 100 (carbon)
e. 400 (cadmium)
f. 1100 (moscovium)
g. 1500 (mendelevium)

5. Rearrange:
a. Iron fuel (fluorine, anagram)
b. Titanium crop (protactinium)
c. Red thorium fur (rutherfordium)
d. Go as erbium (seaborgium)
e. My sodium pear (praseodymium)
f. I am cerium (americium)
g. Francium oil (californium)

\section{References}

1. Meija J. Elemental pub quiz challenge. Anal Bioanal Chem. 2019;411:6531-2. https://doi.org/10.1007/s00216-019-02057-w.

Publisher's note Springer Nature remains neutral with regard to jurisdictional claims in published maps and institutional affiliations. 